Article

\title{
Assessment of Tumorigenic Potential in Mesenchymal-Stem/Stromal-Cell-Derived Small Extracellular Vesicles (MSC-sEV)
}

\author{
Thong Teck Tan ${ }^{1}$, Ruenn Chai Lai ${ }^{1}{ }^{\mathbb{D}}$, Jayanthi Padmanabhan ${ }^{2}$, Wei Kian Sim ${ }^{1}$, Andre Boon Hwa Choo ${ }^{2,3}$ and \\ Sai Kiang $\operatorname{Lim} 1,4, *$
}

1 Institute of Molecular and Cellular Biology, A*STAR, 8A Biomedical Grove, Singapore 138648, Singapore; tan_thong_teck@imcb.a-star.edu.sg (T.T.T.); lai_ruenn_chai@imcb.a-star.edu.sg (R.C.L.); eugene_sim@imcb.a-star.edu.sg (W.K.S.)

2 Bioprocessing Technology Institute, A*STAR, 20 Biopolis Way, Singapore 138668, Singapore; jayanthi_padmanabhan@bti.a-star.edu.sg (J.P.); andre_choo@bti.a-star.edu.sg (A.B.H.C.)

3 Department of Biomedical Engineering, Faculty of Engineering, National University of Singapore (NUS), 9 Engineering Drive 1, Singapore 117575, Singapore

4 Department of Surgery, YLL School of Medicine, National University of Singapore (NUS), 5 Lower Kent Ridge Road, Singapore 119074, Singapore

* Correspondence: lim_sai_kiang@imcb.a-star.edu.sg; Tel.: +65-64-070161

Citation: Tan, T.T.; Lai, R.C.; Padmanabhan, J.; Sim, W.K.; Choo, A.B.H.; Lim, S.K. Assessment of Tumorigenic Potential in Mesenchymal-Stem/Stromal-CellDerived Small Extracellular Vesicles (MSC-sEV). Pharmaceuticals 2021, 14, 345. https://doi.org/10.3390/ ph14040345

Academic Editors: Samir

E.L. Andaloussi, Joel Nordin, André Görgens and Daniel W. Hagey

Received: 4 March 2021

Accepted: 7 April 2021

Published: 9 April 2021

Publisher's Note: MDPI stays neutral with regard to jurisdictional claims in published maps and institutional affiliations.

Copyright: (c) 2021 by the authors. Licensee MDPI, Basel, Switzerland. This article is an open access article distributed under the terms and conditions of the Creative Commons Attribution (CC BY) license (https:/ / creativecommons.org/licenses/by/ $4.0 /)$.

\begin{abstract}
Mesenchymal-stem/stromal-cell-derived small extracellular vesicles (MSC-sEV) have been shown to ameliorate many diseases in preclinical studies. However, translating MSC-sEV into clinical use requires the development of scalable manufacturing processes for highly reproducible preparations of safe and potent MSC-sEVs. A major source of variability in MSC-sEV preparations is EV producer cells. To circumvent variability in producer cells, clonal immortalized MSC lines as EV producer lines are increasingly being used for sEV production. The use of sEVs from immortalized producer cells inevitably raises safety concerns regarding the tumorigenicity or tumor promoting potential of the EV products. In this study, cells from E1-MYC line, a MSC cell line immortalized with the MYC gene, were injected subcutaneously into athymic nude mice. At 84 days post-injection, no tumor formation was observed at the injection site, lungs, or lymph nodes. E1-MYC cells pre-and post-sEV production did not exhibit anchorage-independent growth in soft agar. Daily intraperitoneal injections of 1 or $5 \mu \mathrm{g}$ sEVs from E1-MYC into athymic nude mice with FaDu human head and neck cancer xenografts for 28 days did not promote or inhibit tumor growth relative to the xenograft treated with vehicle control. Therefore, MYC-immortalized MSCs are not tumorigenic and sEVs from these MSCs do not promote tumor growth.
\end{abstract}

Keywords: mesenchymal stem/stromal cell; small extracellullar vesicles; tumorigenicity

\section{Introduction}

Mesenchymal stem/stromal cells (MSCs) are multipotent cells that have the ability to differentiate into cells of the mesochyme lineage such as adipocytes, chondrocytes, and osteocytes. They can be easily isolated from adult tissues and extensively expanded ex vivo. They can differentiate into several cell types such as adipocytes, chondrocytes, and osteocytes. MSCs are currently the most clinically trialed cell type, with $>1200$ trials targeting many disease indications (https: / / clinicaltrials.gov/, accessed on 1 February 2021). The mechanism by which MSC exert their therapeutic effects has evolved over the years. Initially, it was hypothesized that transplanted MSCs home to the site of injury where they engraft and differentiate into the relevant cell types to replace dead or damaged cells. However, it was often observed that despite functional improvements, MSCs or differentiated MSCs were not detected in biologically significant numbers in affected tissues. In 2006, Caplan and Dennis [1] postulated that as MSCs secrete many bioactive molecular species [2], 
MSCs could exert their therapeutic activity through these secreted molecules rather than by direct cellular interactions. In 2008, it was observed that the cardioprotective agent in MSC secretion was enriched in a fraction of MSC-conditioned media with molecular weights (MW) larger than $1000 \mathrm{kDa}$ [3]. This fraction was subsequently found to be rich in 110 and $130 \mathrm{~nm}$ small extracellular vesicles (sEVs), which were termed exosomes at that time [4]. In a similar study, a fraction of MSC conditioned media that was highly enriched for EVs $(80 \mathrm{~nm}$ to $1 \mu \mathrm{m})$ termed microvesicles protected against acute renal tubular injury in a mouse model [5]. As the size range of the reported MSC exosome preparation is a subset of the reported microvesicle preparation, it is possible that both preparations exert their therapeutic effects through similar EV types. Subsequently, head-to-head comparison studies demonstrated that EV preparations were as therapeutically effective as their producer cells in different pre-clinical models [6-8]. Today, it is widely accepted that the therapeutic effects of MSCs are mediated significantly by sEVs with diameters between 50 and $200 \mathrm{~nm}$ [6].

EVs are bi-lipid membrane vesicles that are released into the extracellular space by virtually all cell types. Several EV types have been described to date such as exosomes, microvesicles, ectosomes, membrane particles, exosome-like particles, and apoptotic bodies [7]. The most widely used methods for EV isolation are based on biophysical properties such as size or density. As there are significant overlaps in these properties among the different EV types, most EV preparations are heterogeneous, including MSC-sEV preparations that are enriched in 50-200 nm EVs. MSC-sEVs like most EVs have a characteristic composition of membrane lipids, proteins, and RNAs, and function primarily as intercellular communication vehicles to transfer bioactive proteins, lipids, and nucleic acids between cells to elicit biological responses in recipient cells (as reviewed [8]). We have previously reported that our MSC-sEV preparations contain at least three distinct EV populations, including exosomes derived from the endosomes $[9,10]$. Therefore, we will use the term "MSC exosomes" to refer to our MSC-sEV preparations.

MSC-sEVs have been shown to be efficacious in pre-clinical animal models of human diseases, and many efforts have been made to translate MSC-sEVs into therapeutic products. Several academic societies, namely, the International Society for Cell and Gene Therapy (ISCT), International Society for Extracellular Vesicles (ISEV), and the Society for Clinical Research and Translation of Extracellular Vesicles Singapore (SOCRATES) have organized workshops and written papers to facilitate such efforts [6,11] (Gimona et al., in press). A major consensus on the challenges in manufacturing MSC-sEV preparations of robust reproducible identity and potency is the $\mathrm{sEV}$ producer cell source especially when primary cells are used. Primary cells have finite lifespan and will require frequent replenishment. As there is significant variability between donors and also within donors due to changes in age and health status, cell replenishment will introduce variability in the quality of the producer cells. To mitigate this challenge, we have proposed generating immortalized clonal cell lines with infinite expansion potential [12].

We previously reported the transformation of human ESC-derived MSCs using the MYC gene to immortalize the MSCs and generate a clonal cell line, E1-MYC [12]. E1MYC cells grow faster and have increased telomerase activity while retaining the parental karyotype. The exosomes were highly similar before and after immortalization. Biochemical assay, mass spectrometry analysis, western blot hybridization, and antibody arrays revealed the presence of membrane lipids, namely, cholesterol, sphingomyelin, and phosphatidylcholine, and a proteome of $\sim 1000$ proteins including exosome-associated proteins such as CD81, CD9, and ALIX [4,13,14] Like most EVs, they also have a diverse RNA cargo as determined by array hybridization, reverse transcription polymerase chain reaction (RT-PCR), and RNA sequencing [9,15]. The presence of exosomes, i.e., vesicular particles of 100-200 nm with membrane CD81, was also confirmed by transmission electron microscopy (TEM) and immunoelectron microscopy $[9,16]$.

The use of MSC exosomes from immortalized MSC producer cells inevitably raises safety concerns regarding the tumorigenicity or tumor promoting potential. MSCs generally 
have a strong safety record, as evidenced by the large number of clinical trials using MSCs, and it is reasonable to assume that non-living secretions from MSCs such as EVs would be as safe if not safer. However, immortalization of MSCs with a proto-oncogene such as MYC may alter the safety profile of the MSCs and their secretion and confer tumorigenic or tumor promoting activities on the cells or their secretion.

In this study, we investigated the tumorigenicity of E1-MYC cells, and the effect of E1-MYC-derived exosomes on tumor growth. We tested E1-MYC cells for anchorageindependent growth in soft agar and tumor formation into athymic nude mice. We also tested the effect of E1-MYC-derived exosomes on tumor progression in an athymic nude mouse model of Head and Neck Cancer xenografts.

\section{Results}

\subsection{E1-MYC Does Not Form Tumors In Vivo}

To determine tumorigenicity of E1-MYC, $1 \times 10^{7}$ cells were subcutaneously injected into the right lateral thorax of athymic nude mice. Cells from HT-1080, a fibrosarcoma line, and MRC-5, a fibroblastic line, were used as positive and negative controls, respectively. The mice in the positive control group (HT-1080) were submitted for necropsy on days 7, 11, and 19 post cell injection. On day 21 post cell injection, half of the mice from E1-MYC group and MRC-5 negative control group were submitted for necropsy. The remaining mice were submitted for necropsy on day 84 post cell injection all mice injected with HT-1080 cells developed neoplastic masses at the injection site. One mouse had masses in the lungs, another had masses in the right axillary lymph node, and four had additional smaller masses next to the primary mass. Microscopic examinations of the masses revealed a composition of neoplastic spindloid cells consistent with fibrosarcoma (Table 1). None of the mice injected with E1-MYC and MRC-5 cells showed any lesion at the injection site or in other off-site tissues (Table 1). These results indicate that E1-MYC cells are not tumorigenic.

Table 1. In vivo tumorigenic assay. Pathological observations after implantation of E1-MYC, HT-1080, and MRC-5 in athymic nude mice.

\begin{tabular}{cccc}
\hline Parameter & E1-MYC & HT-1080 & MRC-5 \\
\hline No. of animals & 10 & 10 & 10 \\
\hline & \multicolumn{2}{c}{ Lesion observed } \\
\hline -injection site & 0 & 10 & 0 \\
-axillary lymph & 0 & 1 & 0 \\
-lungs & 0 & 1 & 0 \\
-spleen & 0 & 0 & 0 \\
-liver & 0 & 0 & 0 \\
-kidney & 0 & 0 & 0 \\
-additional site & 0 & 4 & 0 \\
\hline
\end{tabular}

\subsection{Anchorage-Independent Growth Assay}

To evaluate if E1-MYC cells were modified after being used for exosome production, we tested E1-MYC cells pre- and post-exosome production for anchorage-independent growth assay. For MSC exosome production, E1-MYC cells were first expanded in a serum-containing growth medium and then in serum-free chemically defined medium for exosome production. At the end of expansion just before being transferred to serum-free defined medium for exosome production, i.e., pre-production, and after conditioning the defined medium for exosome production, i.e., post-production, cells were harvested and tested for anchorage-independent growth using the CytoSelect 96-well Cell Transformation Assay (\#CBA-130-T, Cell Biolabs Inc., San Diego, CA, USA) with HeLa cells as a positive control. Three different cell densities-1000, 3000, and 9000 cells/well-were seeded in triplicates. After 7 days in culture, HeLa cells showed robust colonies formation but no colony was observed in E1-MYC from either pre- or post-production phases (Figure 1). 
Relative cell concentration in the cultures was determined using a DNA-binding fluorescent dye assay kit, Cyquant quantification. Unlike HeLa cells, E1-MYC cells pre- and postexosome production had minimal anchorage-independent growth.

a

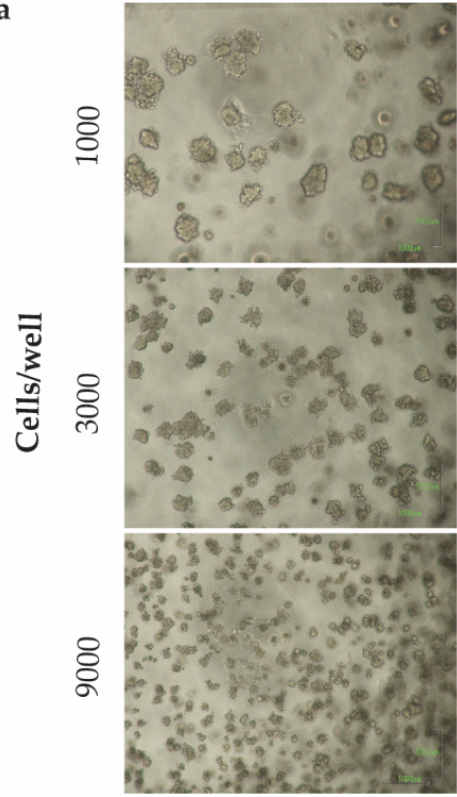

HeLa
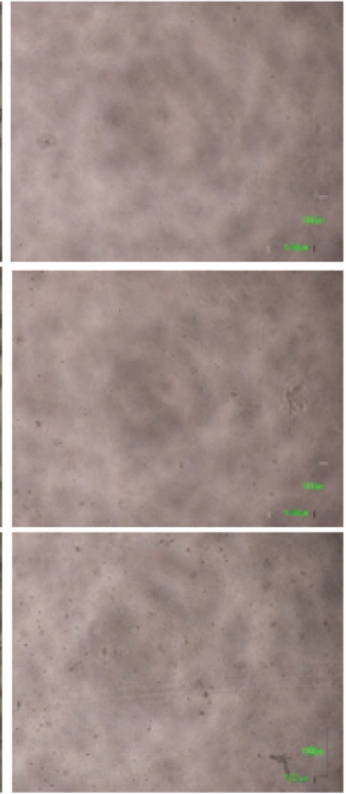

E1-MYC

(pre-production)
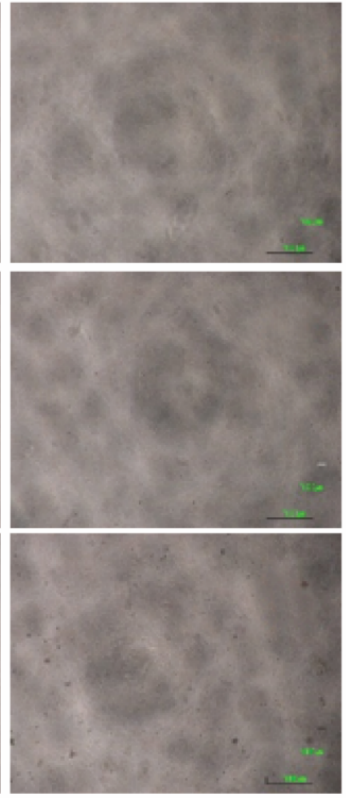

E1-MYC

(post-production)

b

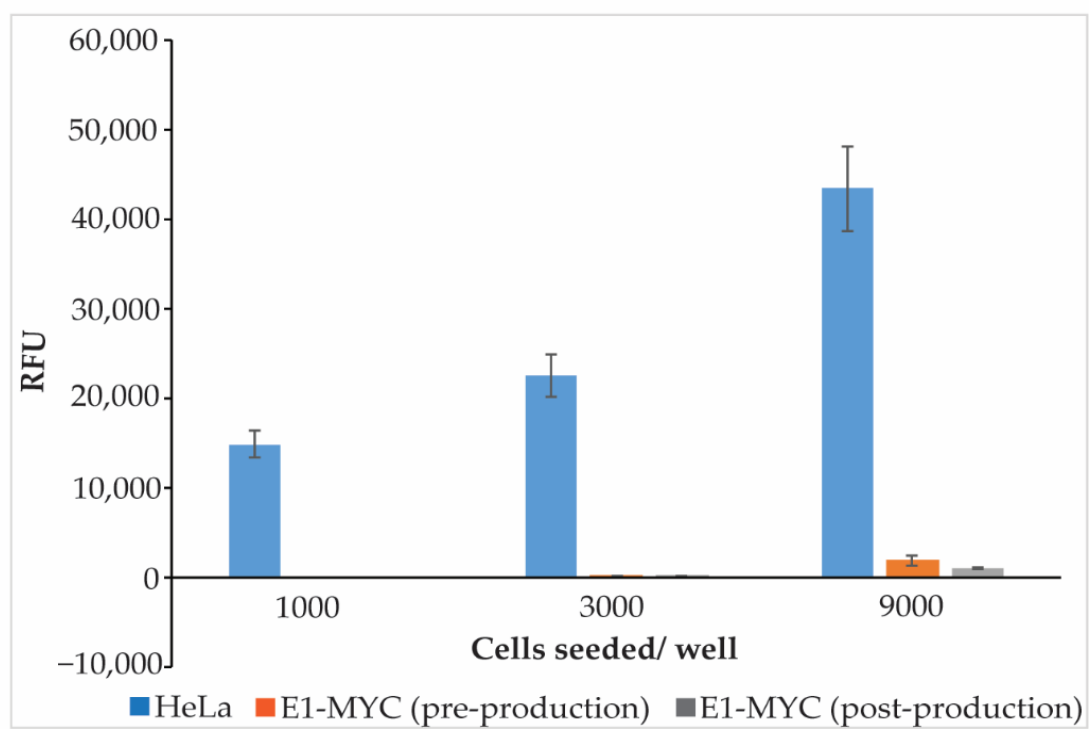

Figure 1. Anchorage-independent growth. HeLa cells and E1-MYC cells from pre- or post-production medium were seeded at three different densities and cultured for 7 days. (a) Representative images (4× magnification) HeLa and E1-MYC cultures after 7 days. (b) Relative cell growth as determined by DNA-binding dye fluorescence after 7 days in culture. Results represent the mean $(n=3$, triplicate for each sample) $\pm \mathrm{SD}$. 


\subsection{The Effects of MSC-sEV on Tumor Progression}

We previously reported that the MYC protein was undetectable in E1-MYC cell secretion and exosomes and that the exosomes were similar before and after MYC transformation, demonstrating that MSC exosomes do not carry MYC oncoprotein to promote tumor growth [12]. As shown above, E1-MYC cells do not form tumors. However, it is possible that $M Y C$ transformation may confer tumor-promoting activity on the exosomes. Here, we test this possibility on a mouse model of FaDu head and neck cancer xenograft. $\mathrm{FaDu}$ cells form low-grade carcinoma (grade I) in nude mice [17] and are therefore well suited to detect possible pro-tumorigenic activity of MSC exosomes. Furthermore, the cells could be grafted subcutaneously to form epidermoid carcinoma. This greatly facilitated continuous measurement and monitoring without the need to sacrifice the mice. After establishment of the xenografts, the mice were injected intraperitoneally daily with vehicle, one or five $\mu \mathrm{g}$ (protein weight) of exosomes for 28 days or 4 weeks (Table 2). Paclitaxel $[18,19]$ (an anti-microtubule agent) was used as a benchmark reference for any anti-tumor activity. As such, the paclitaxel was injected IV twice a week as widely practiced for optimal anti-tumor activity, and not as per administration of exosomes.

Table 2. Treatment regime of tumor model. Group treatments of animals following development of tumor.

\begin{tabular}{cccccc}
\hline Group & No. Mice & Test Material & $\begin{array}{c}\text { Dose } \\
(\mathbf{m g} / \mathbf{k g})\end{array}$ & ROA & Frequency \\
\hline 1 & 8 & Vehicle & $\begin{array}{c}200 \mu \mathrm{L} / \mathrm{per} \\
\text { mouse }\end{array}$ & IP & $\begin{array}{c}\text { Daily for } 4 \\
\text { weeks }\end{array}$ \\
\hline 2 & 8 & Paclitaxel & $15 \mathrm{mg} / \mathrm{kg}$ & IV & $\begin{array}{c}\text { Twice per } \\
\text { week }\end{array}$ \\
\hline 3 & 8 & $\begin{array}{c}\text { E1-MYC } \\
\text { exosomes }\end{array}$ & $\begin{array}{c}1 \mu \mathrm{g} / \mathrm{per} \\
\text { dose }\end{array}$ & IP & $\begin{array}{c}\text { Daily for } 4 \\
\text { weeks }\end{array}$ \\
\hline 4 & 8 & $\begin{array}{c}\text { E1-MYC } \\
\text { exosomes }\end{array}$ & $\begin{array}{c}5 \mu \mathrm{\mu g} / \mathrm{per} \\
\text { dose }\end{array}$ & IP & $\begin{array}{c}\text { Daily for } 4 \\
\text { weeks }\end{array}$ \\
\hline
\end{tabular}

To monitor the overall well-being of the mice, body weight of the mice was measured. There was no statistically significant difference among the body weights of mice receiving vehicle, Paclitaxel, or E1-MYC exosomes (both $1 \mu \mathrm{g}$ and $5 \mu \mathrm{g}$ doses) (Figure 2), suggesting that MSC exosomes from E1-MYC cells did not have any adverse effect on the animals.

To examine the effect of E1-MYC exosomes on tumor growth, tumor volume in each mouse was determined using the formula: tumor vol $=$ length $\times$ width $\times$ width $\times \frac{1}{2}$. Tumor volume in mice receiving either $1 \mu \mathrm{g}$ or $5 \mu \mathrm{g}$ E1-MYC exosomes was not statistically different from those in vehicle- treated mice (Figure 3). On the other hand, mice treated with Paclitaxel had significantly lower tumor volume than mice treated with vehicle from day 5 onwards. At the end of 28 days, the number of surviving mice was 2 for the vehicle group and each of exosome groups. The Paclitaxel group had 8 surviving mice. 


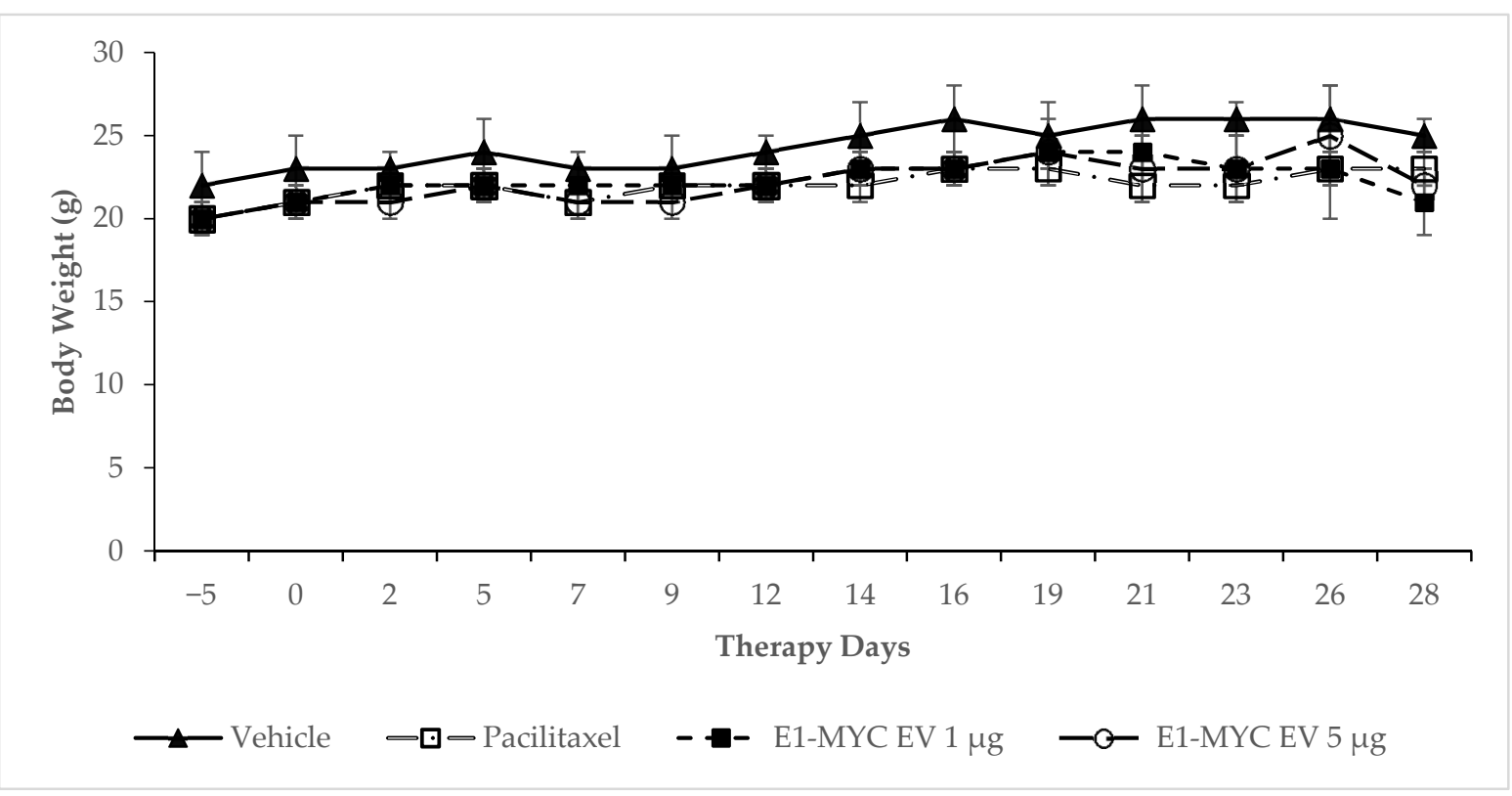

Figure 2. Effect of E1-MYC exosome on body weight. Mice were injected with either vehicle, Paclitaxel, or two different doses of E1-MYC exosome $(1 \mu \mathrm{g}$ or $5 \mu \mathrm{g})$, and their body weight was recorded thrice weekly. No statistically significant differences in body weight between the different treatment groups were observed. Results represent the mean $\pm \mathrm{SD}, n=8$ for all groups from day 0 to day 16. Mice with tumor volume $>2000 \mathrm{~mm}^{3}$ were euthanized and caused the $n$ to gradually drop to 2 for the vehicle and exosome groups at day 28.

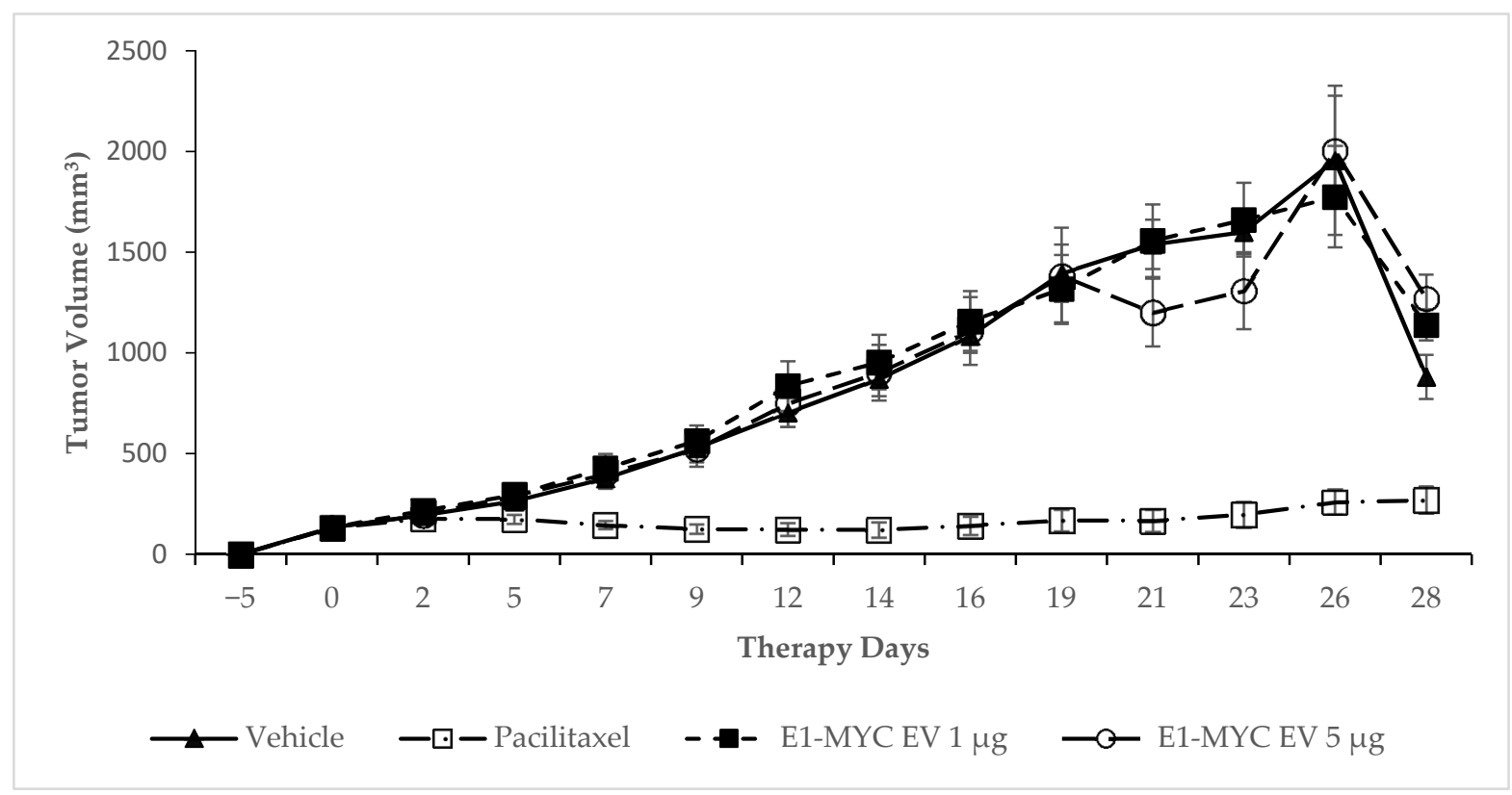

Figure 3. Effect of E1-MYC exosome on tumor growth. Mice were injected with either vehicle, Paclitaxel, or two different doses of E1-MYC exosome $(1 \mu \mathrm{g}$ or $5 \mu \mathrm{g})$, and tumor volume was recorded thrice weekly. Animals treated with E1-MYC exosome had no difference from vehicle control in terms of tumor growth. Results represent the mean \pm SEM, $n=8$ for all groups from day 0 to day 16 . After day 16 , tumor volume in some exosome- or vehicle-treated mice started to exceed $2000 \mathrm{~mm}^{3}$. Euthanizing mice with large tumor volumes reduced the average increase in tumor volume and eventually reduced the tumor volume. At day 28, the vehicle and exosome groups each had only two surviving mice. 


\section{Discussion}

The therapeutic efficacy of MSC-exosomes/sEVs in animal models has generated much optimism about its clinical applications. As with all therapeutics, a primary issue of concern is the safety of the product such as the potential for tumorigenic activity.

MSC transplantations are generally considered safe, as evidenced by the numerous phase 1 safety clinical trials completed to date. Several studies have shown that primary MSC does not form tumors [20-25]. Hence, it is generally assumed that MSC exosomes or sEVs are as safe if not safer. However, the use of primary cells cannot sustain large-scale manufacturing of MSC exosomes with consistent reproducible identity and potency. To mitigate this challenge, we have transformed MSCs with a proto-oncogene, MYC to derive a clonal immortalized cell line [12]. The transformed cells retained the karyotype of the parental cells and produced exosomes with similar characteristics and therapeutic potency as the untransformed cells. Although MYC protein was not detected in the secretion or exosomes, the tumorigenic potential of the transformed cells or their exosome has not been directly addressed.

In this study, we specifically demonstrated that cells from the transformed MSC cell line, E1-MYC, do not form tumors in nude mice and that the cells did not exhibit anchorage-independent growth at pre-or post-exosome production. These observations are consistent with previous study reports that $h-T E R T$ immortalized MSC lines do not induce tumor formation [26-28].

As MSC-EVs are non-living, so they cannot form tumors. However, it is possible that they can affect tumor growth. The effects of MSC-EVs on tumor progression are somewhat controversial. Some studies reported that MSC-EVs inhibited the proliferation of tumors [29-31], while others reported that MSC-EV contributed to tumor growth and metastasis [32,33]. All the MSC-EVs used in these studies were produced by naïve MSCs. In contrast to these studies, MSC exosomes used here were produced by a MYC-transformed MSC, E1-MYC cells. Despite this, these MSC exosomes also did not inhibit or promote tumor growth. The conflicting results on the tumorigenicity of MSC-sEVs could be due to heterogeneity of MSC source, different methodology of EV isolation, or different tumor models used.

In conclusion, our data demonstrate that transformation of MSCs by MYC, a protooncogene, to generate immortalized cells did not confer tumorigenic activity on the cells. Our method for exosome production did not alter the growth of the cells such that they acquired anchorage-independent growth or generate tumor-promoting MSC exosome preparations. Therefore, immortalization of MSCs for exosome production is a viable option for large-scale production of safe exosome preparations for therapeutic use.

\section{Materials and Methods}

\subsection{Culture of MSC and Preparation of MSC-Exosome}

Immortalized E1-MYC 16.3 human ESC-derived mesenchymal stem cells were cultured in DMEM with $10 \%$ fetal calf serum as previously described [12]. To prepare MSC exosomes, $80 \%$ confluent cell culture was grown in a chemically defined medium for three days to generate a conditioned medium $(\mathrm{CM})$ as previously described $[4,34,35]$. The defined medium was prepared as follows: $480 \mathrm{~mL}$ DMEM (Thermo Fisher, \#31053), 5 mL NEAA (Thermo Fisher, \#11140-050), 5 mL L Glutamine (Thermo Fisher, \#25030-081), 5 mL Sodium Pyruvate (Thermo Fisher, \#11360), $5 \mathrm{~mL}$ ITS-X (Thermo Fisher, \#51500-056), and $0.5 \mathrm{~mL}$ 2-ME (Thermo Fisher, \#21985-02). This was supplemented with $0.1 \mathrm{~mL} b F G F(0.5 \mathrm{ng} / \mu \mathrm{L}$ $0.2 \%$ BSA in PBS (+) and $0.005 \mathrm{~mL}$ PDGF $(100 \mathrm{ng} / \mu \mathrm{L}$ PBS (+)). These latter components were obtained as follows: Bovine Serum Albumin or BSA (Sigma-Aldrich, \#A9647), PDGF (AB CYTOLAB, \#100-00), bFGF (Thermo Fisher, \#13256-029), and PBS (+) (Thermo Fisher, $\# 14040-133)$. The CM was size fractionated and concentrated $50 \times$ by tangential flow filtration using a membrane with a molecular weight cut-off (MWCO) of $100 \mathrm{kDa}$ (Sartorius, \#VS15T41) to generate the MSC exosome preparation. The MSC exosome preparation was assayed for protein concentration using a Coomassie Plus (Bradford) Assay 
Kit (ThermoFisher Scientific, \#23236), and the exosome preparations were quantified by the protein concentration. All batches of exosome used in this study were determined by Nanoparticle tracking analysis on a ZetaView instrument (Particle Matrix GmbH, Germany) to have $1.46 \times 10^{11} \pm 2.43 \times 10^{10}$ particles per ug protein and particle modal size of $138.62 \pm 4.45 \mathrm{~nm}$ using the parameters (sensitivity $=90$, shutter $=70$, frame rate $=30$, $\min$ brightness $=25$, $\min$ area $=5$, max area $=1000$ ). Each batch of MSC exosome preparation was also confirmed by western or ELISA to have CD81 and CD73. The exosome preparations were filtered with a $0.22 \mu \mathrm{m}$ filter (Merck Millipore, Billerica, MA, USA) and stored in $-20{ }^{\circ} \mathrm{C}$ freezer until they were used in 4.2. in vitro tumorigenicity assay.

\subsection{In Vitro Tumorigenicity Assay}

To evaluate tumorigenicity of E1-MYC cells pre and post exosome production, anchorageindependent growth was assessed with the soft agar colony formation assay using the CytoSelect ${ }^{\mathrm{TM}}$ 96-well Cell Transformation Assay (\#CBA-130-T, Cell Biolabs Inc., San Diego, CA, USA). Briefly, a $0.6 \%$ base agar layer containing DMEM and FBS was prepared in a 96-well plate. E1-MYC cells from expansion and production phases, and HeLa cells, were suspended in DMEM containing FBS and 0.4\% agar solution and plated onto the base layer. Three different cell densities were plated in triplicates, 1000, 3000, and 9000 cells/well. Cells were incubated at $37^{\circ} \mathrm{C}$ with $5 \% \mathrm{CO}_{2}$ for 7 days before quantitation with a CyQuant ${ }^{\circledR} \mathrm{GR}$ Dye assay kit (\#1010-T, Cell Biolabs Inc., San Diego, CA, USA).

\subsection{Cell Implantation and Histological Evaluation for Tumor Formation}

In vivo tumorigenicity assay and histological evaluation were performed by Charles River Laboratories (Protocol code: PR-4-10). Briefly, three groups of ten athymic nude mice were subcutaneously injected with $1 \times 10^{7}$ of either E1-MYC, a positive control fibrosarcoma cell line HT-1080, or a negative control fibroblast cell line MRC-5. Animals in the positive control group (HT-1080) were submitted for necropsy on days 7, 11, and 19 post cell injection. On day 21 post cell injection, half of the mice from E1-MYC group and MRC- 5 negative control group were submitted for necropsy. The remaining mice were submitted for necropsy on day 84 post cell injection. To examine the tumorigenic and biodistribution potential of the cells injected, tissues from the injection site, right axillary lymph lode, lungs, liver, spleen, kidneys, and any general gross lesions were harvested. The harvested tissues were fixed in formalin, embedded in paraffin, and sectioned at five microns, mounted on a glass slide and stained with hematoxylin and eosin.

\subsection{Pro-Tumorigenic Activity of MSC-sEV}

Pro-tumorigenic activity of MSC-sEV in a Fadu xenograft model in athymic nude mice for human head and neck carcinoma were done by a CRO, Washington Biotechnology Inc (Protocol code: 17-074.4). Four groups of 8 mice were injected with $5 \times 10^{6}$ Fadu cells subcutaneously into the right flank of each mouse. Upon development of tumors of sufficient size, the dosing regimen (Table 2) was initiated. The animal weights and tumor measurements were recorded three times a week. The xenograft tumors were measured with a digital caliper. Tumor volume was calculated using the formula: tumor vol $=$ length $\times$ width $\times$ width $\times \frac{1}{2}$. During the study, mice with oversize tumor $\left(>2000 \mathrm{~mm}^{3}\right)$ were euthanized and removed from the study. Tumor sizes were analyzed using Student's $t$-test. $p$-values $<0.05$ were considered as statistically significant.

Author Contributions: Conceptualization, S.K.L. and A.B.H.C.; methodology, T.T.T., R.C.L., J.P., and W.K.S.; investigation, T.T.T., R.C.L.; writing-original draft preparation, T.T.T., R.C.L.; writingreview and editing, S.K.L.; supervision, S.K.L.; funding acquisition, S.K.L. and A.B.H.C. All authors have read and agreed to the published version of the manuscript.

Funding: This study was supported by IAF-ICP funding (\#I1801E0019, developing exosomes for Therapy, A*STAR, Singapore) and IAF-PP funding (\#H19H6a0026, translating MSC exosomes into pharmaceuticals (TEx2Pharm), A*STAR, Singapore. 
Institutional Review Board Statement: 1. Cell Implantation and Histological Evaluation for Tumor Formation: the study was conducted according to the guidelines of the Declaration of Helsinki, and approved by the Institutional Review Board (or Ethics Committee) of CHARLES RIVER (protocol code PR-4-10 and effective date 11 Mar 2014); 2. Pro-tumorigenic Activity of MSC-sEV: the study was conducted according to the guidelines of the Declaration of Helsinki, and approved by the Institutional Review Board (or Ethics Committee) of WASHINGTON BIOTECHNOLOGY (protocol code 17-074.4 and date of approval 5 Jan 2018).

Informed Consent Statement: Not applicable.

Data Availability Statement: Data is contained within the article.

Conflicts of Interest: S.K.L. is a founder director of Paracrine Therapeutics.

\section{References}

1. Caplan, A.I.; Dennis, J.E. Mesenchymal stem cells as trophic mediators. J. Cell. Biochem. 2006, 98, 1076-1084. [CrossRef] [PubMed]

2. Haynesworth, S.E.; Baber, M.A.; Caplan, A.I. Cytokine expression by human marrow-derived mesenchymal progenitor cells in vitro: Effects of dexamethasone and IL-1 alpha. J. Cell Physiol. 1996, 166, 585-592. [CrossRef]

3. Timmers, L.; Lim, S.K.; Arslan, F.; Armstrong, J.S.; Hoefer, I.E.; Doevendans, P.A.; Piek, J.J.; El Oakley, R.M.; Choo, A.; Lee, C.N.; et al. Reduction of myocardial infarct size by human mesenchymal stem cell conditioned medium. Stem Cell Res. 2008, 1, $129-137$. [CrossRef]

4. Lai, R.C.; Arslan, F.; Lee, M.M.; Sze, N.S.K.; Choo, A.; Chen, T.S.; Salto-Tellez, M.; Timmers, L.; Lee, C.N.; El Oakley, R.M.; et al. Exosome secreted by MSC reduces myocardial ischemia/reperfusion injury. Stem Cell Res. 2010, 4, 214-222. [CrossRef] [PubMed]

5. Bruno, S.; Grange, C.; Deregibus, M.C.; Calogero, R.A.; Saviozzi, S.; Collino, F.; Morando, L.; Busca, A.; Falda, M.; Bussolati, B.; et al. Mesenchymal stem cell-derived microvesicles protect against acute tubular injury. J. Am. Soc. Nephrol. 2009, 20, $1053-1067$. [CrossRef] [PubMed]

6. Witwer, K.W.; Van Balkom, B.W.; Bruno, S.; Choo, A.; Dominici, M.; Gimona, M.; Hill, A.F.; De Kleijn, D.; Koh, M.; Lai, R.C.; et al. Defining mesenchymal stromal cell (MSC)-derived small extracellular vesicles for therapeutic applications. J. Extracell. Vesicles 2019, 8, 1609206. [CrossRef] [PubMed]

7. Thery, C.; Ostrowski, M.; Segura, E. Membrane vesicles as conveyors of immune responses. Nat. Rev. Immunol. 2009, 9, 581-593. [CrossRef]

8. Lai, R.C.; Yeo, R.W.; Lim, S.K. Mesenchymal stem cell exosomes. Semin. Cell Dev. Biol. 2015, 40, 82-88. [CrossRef]

9. Lai, R.C.; Tan, S.S.; Yeo, R.W.Y.; Choo, A.B.H.; Reiner, A.T.; Su, Y.; Shen, Y.; Fu, Z.; Alexander, L.; Sze, S.K.; et al. MSC secretes at least $3 \mathrm{EV}$ types each with a unique permutation of membrane lipid, protein and RNA. J. Extracell. Vesicles 2016, 5, 29828. [CrossRef]

10. Tan, S.S.; Yin, Y.; Lee, T.; Lai, R.C.; Yeo, R.W.Y.; Zhang, B.; Choo, A.; Lim, S.K. Therapeutic MSC exosomes are derived from lipid raft microdomains in the plasma membrane. J. Extracell. Vesicles 2013, 2. [CrossRef]

11. Reiner, A.T.; Witwer, K.W.; Van Balkom, B.W.M.; De Beer, J.; Brodie, C.; Corteling, R.L.; Gabrielsson, S.; Gimona, M.; Ibrahim, A.G.; De Kleijn, D.; et al. Concise Review: Developing Best-Practice Models for the Therapeutic Use of Extracellular Vesicles. Stem Cells Transl. Med. 2017, 6, 1730-1739. [CrossRef] [PubMed]

12. Chen, T.S.; Arslan, F.; Yin, Y.; Tan, S.S.; Lai, R.C.; Choo, A.B.H.; Padmanabhan, J.; Lee, C.N.; De Kleijn, D.P.V.; Lim, S.K. Enabling a robust scalable manufacturing process for therapeutic exosomes through oncogenic immortalization of human ESC-derived MSCs. J. Transl. Med. 2011, 9, 47. [CrossRef]

13. Lai, R.C.; Tan, S.S.; Teh, B.J.; Sze, S.K.; Arslan, F.; De Kleijn, D.P.; Choo, A.; Lim, S.K. Proteolytic Potential of the MSC Exosome Proteome: Implications for an Exosome-Mediated Delivery of Therapeutic Proteasome. Int. J. Proteom. 2012, $2012,971907$. [CrossRef]

14. Lai, R.C.; Yeo, R.W.Y.; Tan, S.S.; Zhang, B.; Yin, Y.; Sze, N.S.K.; Choo, A.; Lim, S.K. Mesenchymal Stem Cell Exosomes: The Future MSC-Based Therapy? In Mesenchymal Stem Cell Therapy; Chase, L.G., Vemuri, M.C., Eds.; Humana Press: Totowa, NJ, USA, 2013; pp. 39-61.

15. Chen, T.S.; Lai, R.C.; Lee, M.M.; Choo, A.B.H.; Lee, C.N.; Lim, S.K. Mesenchymal stem cell secretes microparticles enriched in pre-microRNAs. Nucleic Acids Res. 2009, 38, 215-224. [CrossRef]

16. Accarie, A.; L'Homme, B.; Benadjaoud, M.A.; Lim, S.K.; Guha, C.; Benderitter, M.; Tamarat, R.; Sémont, A. Extracellular vesicles derived from mesenchymal stromal cells mitigate intestinal toxicity in a mouse model of acute radiation syndrome. Stem Cell Res. Ther. 2020, 11, 371. [CrossRef]

17. Rangan, S.R. A new human cell line (FaDu) from a hypopharyngeal carcinoma. Cancer 1972, 29, 117-121. [CrossRef]

18. Wani, M.C.; Taylor, H.L.; Wall, M.E.; Coggon, P.; McPhail, A.T. Plant antitumor agents. VI. The isolation and structure of taxol, a novel antileukemic and antitumor agent from Taxus brevifolia. J. Am. Chem. Soc. 1971, 93, 2325-2327. [CrossRef] [PubMed]

19. Long, H.J. Paclitaxel (Taxol): A novel anticancer chemotherapeutic drug. Mayo Clin. Proc. 1994, 69, 341-345. [CrossRef] 
20. Vilalta, M.; Dégano, I.R.; Bago, J.R.; Gould, D.; Dos Santos, M.V.F.; García-Arranz, M.; Ayats, R.; Fuster, C.; Chernajovsky, Y.; García-Olmo, D.; et al. Biodistribution, long-term survival, and safety of human adipose tissue-derived mesenchymal stem cells transplanted in nude mice by high sensitivity non-invasive bioluminescence imaging. Stem Cells Dev. 2008, 17, 993-1003. [CrossRef]

21. Lopez-Iglesias, P.; Blázquez-Martínez, A.; Fernández-Delgado, J.; Regadera, J.; Nistal, M.; De Miguel, M.P. Short and long term fate of human AMSC subcutaneously injected in mice. World J. Stem Cells 2011, 3, 53-62. [CrossRef]

22. Von Bahr, L.; Batsis, I.; Moll, G.; Hägg, M.; Szakos, A.; Sundberg, B.; Uzunel, M.; Ringden, O.; Le Blanc, K. Analysis of tissues following mesenchymal stromal cell therapy in humans indicates limited long-term engraftment and no ectopic tissue formation. Stem Cells 2012, 30, 1575-1578. [CrossRef]

23. MacIsaac, Z.M.; Shang, H.; Agrawal, H.; Yang, N.; Parker, A.; Katz, A.J. Long-term in-vivo tumorigenic assessment of human culture-expanded adipose stromal/stem cells. Exp. Cell Res. 2012, 318, 416-423. [CrossRef]

24. Wang, Y.; Zhang, Z.; Chi, Y.; Zhang, Q.; Xu, F.; Yang, Z.; Meng, L.; Yang, S.; Mao, A.; Zhang, J.; et al. Long-term cultured mesenchymal stem cells frequently develop genomic mutations but do not undergo malignant transformation. Cell Death Dis. 2013, 4, e950. [CrossRef] [PubMed]

25. Scheers, I.; Lombard, C.; Paganelli, M.; Campard, D.; Najimi, M.; Gala, J.-L.; Decottignies, A.; Sokal, E. Human umbilical cord matrix stem cells maintain multilineage differentiation abilities and do not transform during long-term culture. PLoS ONE 2013, 8, e71374. [CrossRef]

26. Simonsen, J.L.; Rosada, C.; Serakinci, N.; Justesen, J.; Stenderup, K.; Rattan, S.I.; Jensen, T.G.; Kassem, M. Telomerase expression extends the proliferative life-span and maintains the osteogenic potential of human bone marrow stromal cells. Nat. Biotechnol. 2002, 20, 592-596. [CrossRef]

27. Liu, T.M.; Ng, W.M.; Tan, H.S.; Vinitha, D.; Yang, Z.; Fan, J.B.; Zou, Y.; Hui, J.H.; Lee, E.H.; Lim, B. Molecular basis of immortalization of human mesenchymal stem cells by combination of $\mathrm{p} 53$ knockdown and human telomerase reverse transcriptase overexpression. Stem Cells Dev. 2013, 22, 268-278. [CrossRef]

28. Skarn, M.; Noordhuis, P.; Wang, M.-Y.; Veuger, M.; Kresse, S.H.; Egeland, E.V.; Micci, F.; Namløs, H.M.; Håkelien, A.-M.; Olafsrud, S.M.; et al. Generation and characterization of an immortalized human mesenchymal stromal cell line. Stem Cells Dev. 2014, 23 , 2377-2389. [CrossRef]

29. Bruno, S.; Collino, F.; Deregibus, M.C.; Grange, C.; Tetta, C.; Camussi, G. Microvesicles derived from human bone marrow mesenchymal stem cells inhibit tumor growth. Stem Cells Dev. 2013, 22, 758-771. [CrossRef]

30. Lee, J.K.; Park, S.-R.; Jung, B.-K.; Jeon, Y.-K.; Lee, Y.-S.; Kim, M.-K.; Kim, Y.-G.; Jang, J.-Y.; Kim, C.-W. Exosomes derived from mesenchymal stem cells suppress angiogenesis by down-regulating VEGF expression in breast cancer cells. PLoS ONE 2013, 8, e84256. [CrossRef]

31. Wu, S.; Ju, G.-Q.; Du, T.; Zhu, Y.-J.; Liu, G.-H. Microvesicles derived from human umbilical cord Wharton's jelly mesenchymal stem cells attenuate bladder tumor cell growth in vitro and in vivo. PLoS ONE 2013, 8, e61366.

32. Roccaro, A.M.; Sacco, A.; Maiso, P.; Azab, A.K.; Tai, Y.-T.; Reagan, M.; Azab, F.; Flores, L.M.; Campigotto, F.; Weller, E.; et al. BM mesenchymal stromal cell-derived exosomes facilitate multiple myeloma progression. J. Clin. Investig. 2013, 123, $1542-1555$. [CrossRef]

33. Rodini, C.O.; Da Silva, P.B.G.; Assoni, A.F.; Carvalho, V.M.; Okamoto, O.K. Mesenchymal stem cells enhance tumorigenic properties of human glioblastoma through independent cell-cell communication mechanisms. Oncotarget 2018, 9, $24766-24777$. [CrossRef] [PubMed]

34. Lai, R.C.; Arslan, F.; Tan, S.S.; Tan, B.; Choo, A.; Lee, M.M.; Chen, T.S.; Teh, B.J.; Eng, J.K.L.; Sidik, H.; et al. Derivation and characterization of human fetal MSCs: An alternative cell source for large-scale production of cardioprotective microparticles. J. Mol. Cell. Cardiol. 2010, 48, 1215-1224. [CrossRef]

35. Sze, S.K.; de Kleijn, D.P.V.; Lai, R.C.; Tan, E.K.W.; Zhao, H.; Yeo, K.S.; Low, T.Y.; Lian, Q.; Lee, C.N.; Mitchell, W.; et al. Elucidating the secretion proteome of human embryonic stem cell-derived mesenchymal stem cells. Mol. Cell. Proteom. 2007, 6, 1680-1689. [CrossRef] 